University of Nebraska - Lincoln

DigitalCommons@University of Nebraska - Lincoln

US Department of Energy Publications

U.S. Department of Energy

1989

\title{
Subsurface transport of Contaminants
}

John E. McCarthy

Oak Ridge National Laboratory

John M. Zachara

Pacific Northwest National Laboratory, john.zachara@pnl.gov

Follow this and additional works at: https://digitalcommons.unl.edu/usdoepub

Part of the Bioresource and Agricultural Engineering Commons

McCarthy, John E. and Zachara, John M., "Subsurface transport of Contaminants" (1989). US Department of Energy Publications. 175.

https://digitalcommons.unl.edu/usdoepub/175

This Article is brought to you for free and open access by the U.S. Department of Energy at DigitalCommons@University of Nebraska - Lincoln. It has been accepted for inclusion in US Department of Energy Publications by an authorized administrator of DigitalCommons@University of Nebraska - Lincoln. 

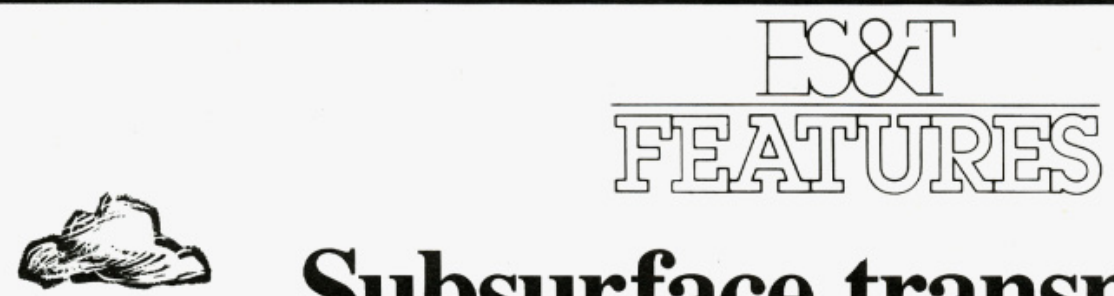

\section{Subsurface transport of contaminants}

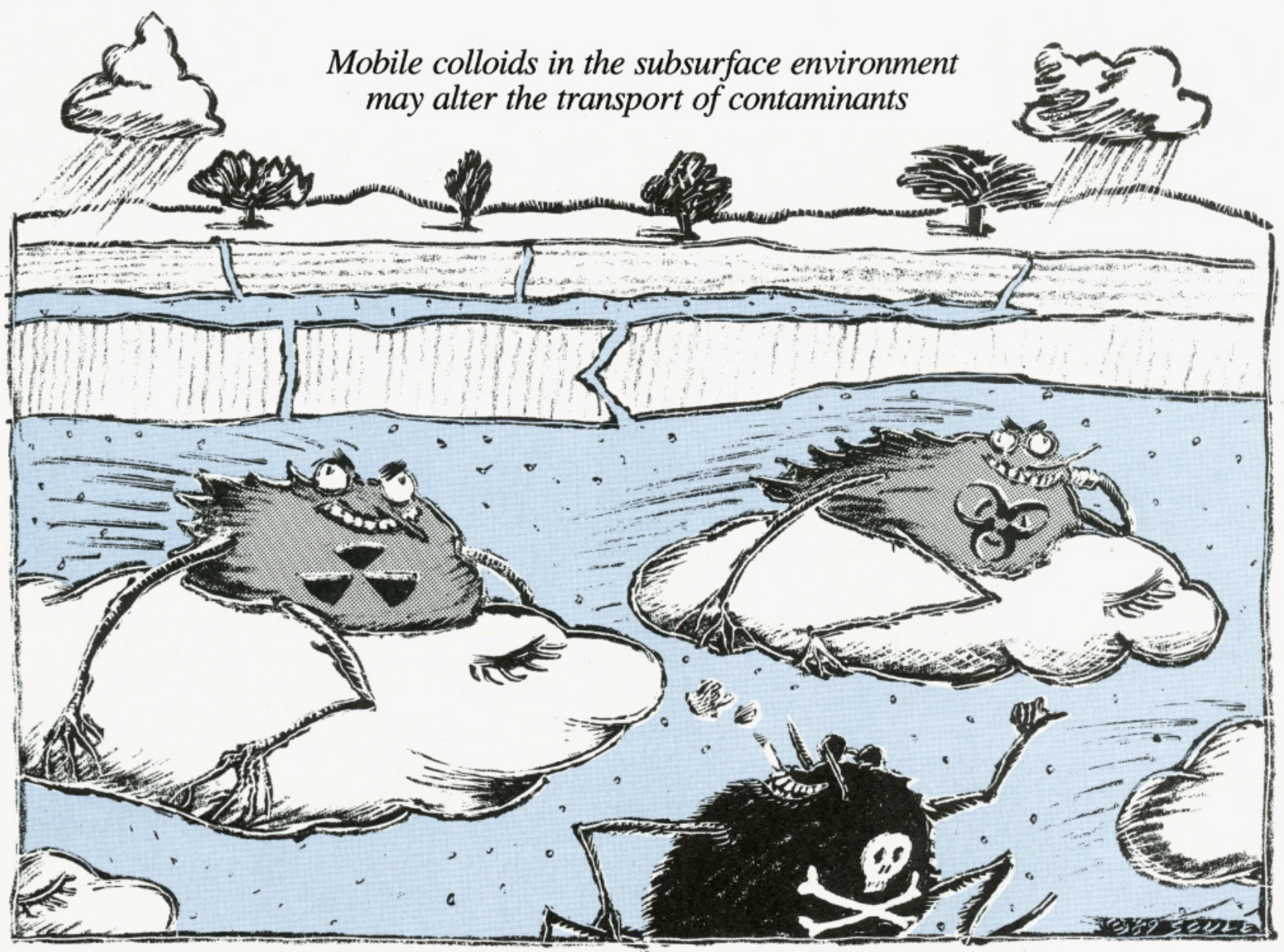

John F. McCarthy

Oak Ridge National Laboratory

Oak Ridge, TN 37831-6036

John M. Zachara

Battelle Pacific Northwest Laboratory

Richland, WA 99352

Contaminants originating from human activities have entered the subsurface environment through waste disposal practices, spills, and land application of chemicals. The establishment of effective disposal and isolation procedures for chemical wastes, the protection of public health, and the amelioration of subsurface contamination rely on the ability to predict the velocity at which contaminants move through the vadose (unsaturated) and saturated zones. However, attempts to describe and predict contaminant transport cannot succeed if major pathways and mechanisms for transport are not defined.

Most approaches to describing and predicting the movement of contaminants treat groundwater as a two-phase system in which contaminants partition between immobile solid constituents and the mobile aqueous phase. Contaminants that are sparingly soluble in water and that have a strong tendency to bind to aquifer media are assumed to be retarded (to move much more slowly than the rate at which groundwater flows) (Figure 1a).
Many contaminants readily sorb to immobile aquifer media and therefore are considered to be virtually immobile in the subsurface and to present little danger to groundwater supplies. For example, in soil and aquifer material, many metals and radionuclides bind strongly to mineral components; furthermore, many nonpolar organic contaminants tend to bind to particulate organic matter. Colloids in the solid phase, however, also may be mobile in subsurface environments. Because the composition of colloids is expected to be chemically similar to that of the surfaces of immobile aquifer material, these particles also could sorb organic and inorganic contaminants and stabilize them in the mobile phase. The col- 
loids act as a third phase that can increase the amount of contaminant that the flow of groundwater can transport (see Figure lb).

This article calls attention to the potentially critical but poorly understood role of colloids in facilitating contaminant transport. Failure to account for this mode of transport can lead to serious underestimates of the distances that contaminants will migrate. For example, at a Defense Programs site at Los Alamos National Laboratory, plutonium and americium disposed of at a liquid seepage site migrated up to $30 \mathrm{~m}$ (1); predictions that were based on laboratory measurements of radionuclide binding to immobile subsurface materials and that ignored colloids forecast that migration would be limited to a few millimeters. At another site at Los Alamos, not only were plutonium and americium detected in monitoring wells over a mile from a liquid waste outfall, but the transported radionuclides were shown by ultrafiltration to be present as colloids ( 0.025 to $0.45 \mu \mathrm{m}$ in diameter) (2).

Colloids are particles with diameters less than $10 \mu \mathrm{m}$ (Figure 2) (3). A variety of organic and inorganic materials exist as colloids in groundwater, including macromolecular components of "dissolved" organic carbon (DOC) such as humic substances, "biocolloids" such as microorganisms, microemulsions of nonaqueous phase liquids, mineral precipitates and weathering products, precipitates of transuranic elements such as plutonium, and rock and mineral fragments. In this article, colloidal materials suspended in water are referred to as particles; the term media or matrix refers to the fixed bed of porous or fractured subsurface material through which a solution may flow.

We will discuss the genesis and stabilization of groundwater colloids and the chemical and hydrologic factors controlling their transport through porous media; we also will assess the evidence that contaminants bind to mobile colloids in groundwater. We then will review the status of current capabilities to incorporate the facilitated transport by colloids into predictive hydrogeochemical models as well as the potential application of colloid mobilization and deposition to waste management strategies. Finally, we identify research that is needed to understand and predict the role of colloids in the subsurface transport of contaminants. First of all, however, it is important to call attention to the critical caveat in research on groundwater colloids: Are colloids in water recovered from a well bore representative of those present within the porous media?
FIGURE 1

Contaminant movement in groundwater

(a) Two-phase system

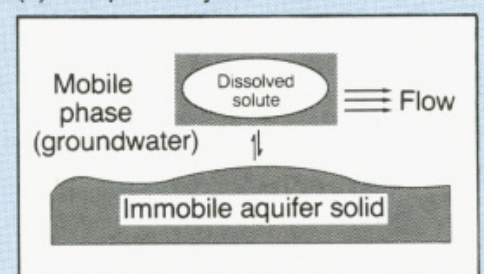

(b) Three-phase system

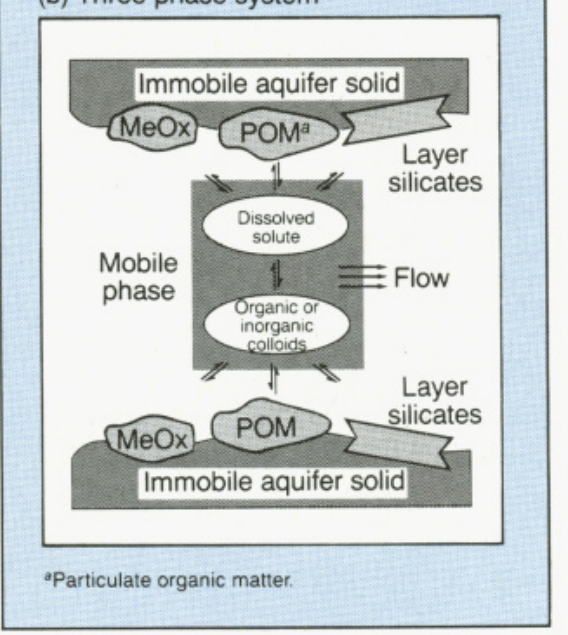

\section{Sampling difficulties}

Existing information is sufficient to raise concerns about the potential effect of colloids on the mobility of groundwater contaminants. Nevertheless, current approaches to monitoring and predicting contaminant transport generally ignore colloid-facilitated transport mechanisms because little, if any, information is available on the abundance and identity of colloids in groundwater, their tendency to bind contaminants, or their mobility in subsurface systems. Our understanding of the subsurface environment is limited by the techniques we use to characterize it, and nowhere in geochemistry is this more evident than in the study of subsurface colloids.

Drilling redistributes material, creates fine particles, introduces materials (drilling muds, for example) into the borehole, and provides a conduit for air to contact groundwater. Sampling procedures also can introduce artifacts, including the removal of existing colloids, the creation of colloids during sampling, or changes in the chemical and physical properties of the natural colloids because of alterations in oxygen and carbon dioxide $\left(\mathrm{CO}_{2}\right)$ content, temperature, $\mathrm{pH}$, Eh (redox potential), and light as the groundwater is brought to the surface. For example, introduction of oxygen can lead to the produc- tion of colloids, especially $\mathrm{Fe}(\mathrm{III})$ oxides $(4,5)$; the rapid pumping of a well can force otherwise immobile aquifer solids into the well or can disrupt fragile colloidal aggregates $(6,7)$. Clearly, the issue of proper sampling protocols is central to progress in evaluating the role of colloids in contaminant transport. Critical evaluation of the occurrence, composition, nature, and abundance of subsurface colloids requires testing and validation of sampling methodologies that correctly sample mobile material in groundwater so that suspended colloidal particles are included but immobile particles are excluded.

\section{Colloidal material in groundwater}

The occurrence of colloids in groundwater should not be surprising; colloidal-sized substances are known to be associated with geologic matrices. Coarse-grained aquifer material can contain up to $5 \%$ clay-sized materials $(<2 \mu \mathrm{m})$ that may be detrital (contained in the original parent geologic material) or authigenic (formed in situ through geochemical alteration of primary mineral solids in groundwater zones). Detrital colloidal material can be diverse in nature and is a function of the depositional environment as well as of the mineralogic composition of the original source geologic material.

Various layer silicates, as well as iron and aluminum oxides, can be detrital in subsurface sediments. Authigenic colloidal-sized particles composed of secondary hydrous oxides, aluminosilicates, and silica, as well as complex mixtures and solid solutions of these phases, also form on the surfaces of larger mineral grains as a result of the alteration of thermodynamically unstable primary minerals. Other solids such as calcite and iron sulfide have been observed to form directly as a result of downgradient changes in groundwater hydrochemistry. Surface analyses of sediments typically show various colloidal-sized secondary precipitates coating larger grains.

The presence of a clay-sized fraction in many aquifer materials suggests that the colloidal fraction is not intrinsically mobile. Indeed, the isolation of claysized materials from subsurface sediments often requires the use of ultrasonic or chemical dispersion because the fines are aggregated or are bound to larger particles by cementing agents or electrostatic forces. Typical cementing agents include iron oxides, carbonates, and silica. Stable aggregates of layer silicates are promoted by saturation with divalent ions, such as $\mathrm{Ca}^{2+}$, that coagulate single crystallites.

A first but essential step in the genesis of mobile colloids in groundwater is 
FIGURE 2

Size spectrum of waterborne particles

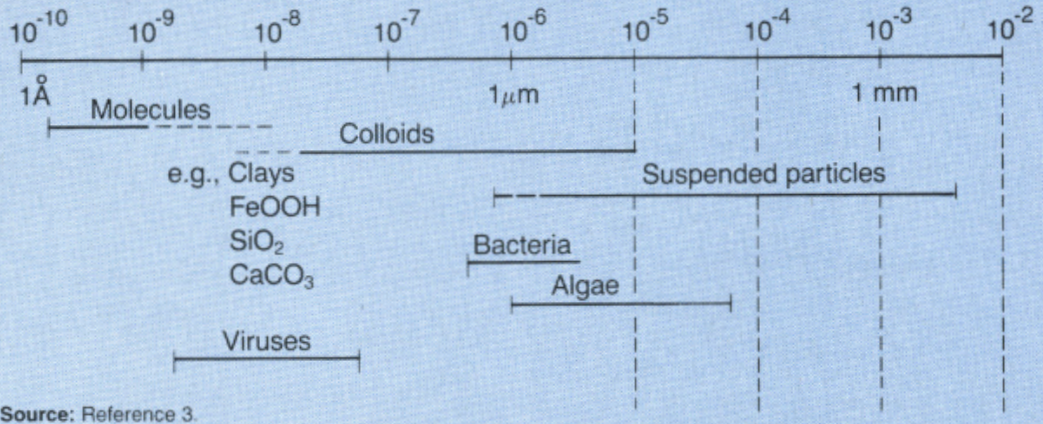

Source: Reference 3.

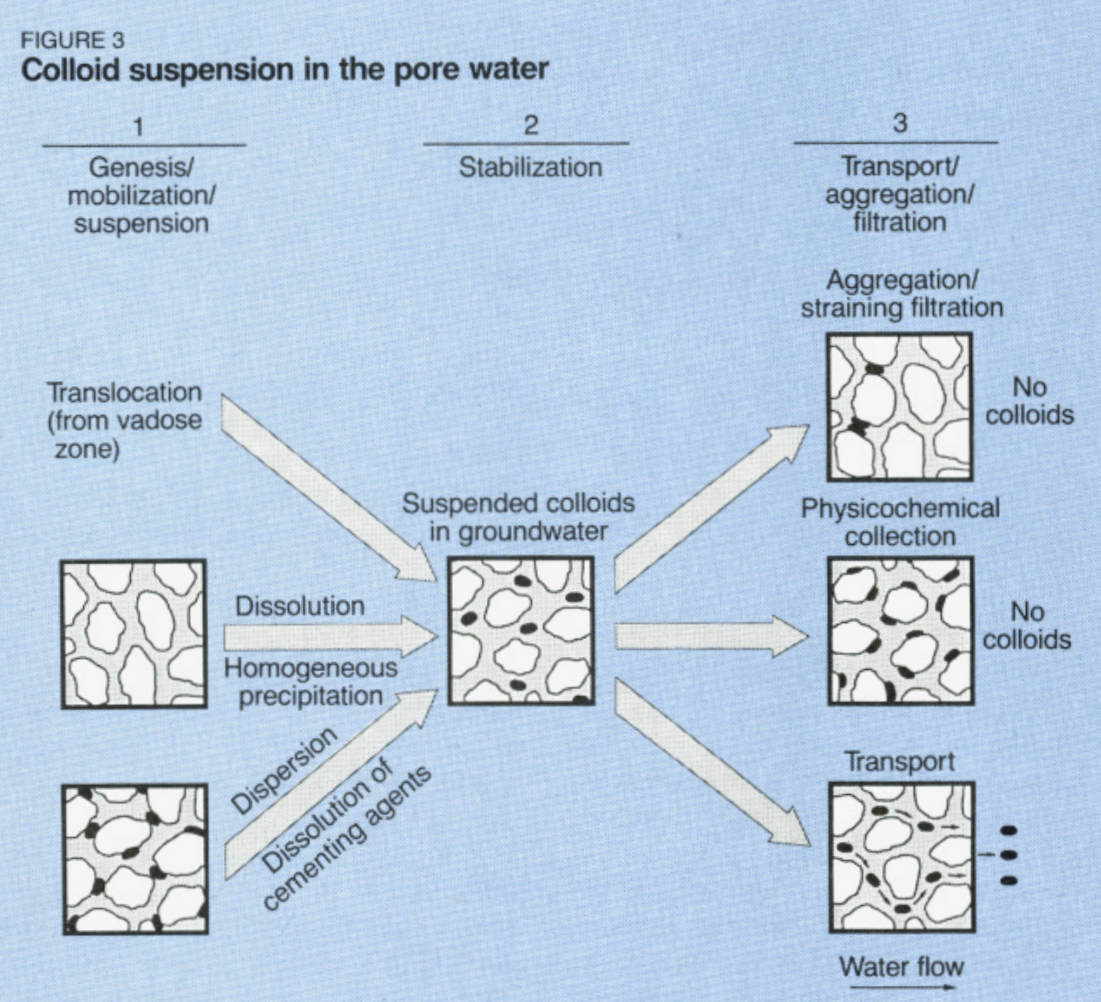

the formation of a colloid suspension in the pore water (Figure 3). This step can involve a number of mechanisms including the homogeneous nucleation of inorganic solids in the fluid phase, the release of colloidal material from the geologic matrix, and the translocation of inorganic and organic substances from the vadose or recharge zone.

Colloidal-sized precipitates can form in the aqueous phase if gradients in geochemical parameters such as groundwater $\mathrm{pH}$, ion composition, redox potential, or $\mathrm{CO}_{2}$ partial pressure indice supersaturation with respect to readily precipitable solid phases. Such gradients may result either from natural geochemical processes (including microbiological activity that can reduce redox potential or influence $\mathrm{CO}_{2}$ partial neath a sewage infiltration basin (8). Also, iron oxide colloids have been observed to precipitate in groundwaters as a result of both $\mathrm{pH}$ changes and oxygenation (9). Moreover, certain strongly hydrolyzing radionuclides form colloids whose particles are nanometer-sized (10).

Colloidal materials also can be released to groundwater as a result of geochemical and biologic processes acting upon larger inorganic or organic particulate materials in the aquifer matrix. Organic macromolecules such as humic substances can be made soluble from kerogen, bitumen, or lignitic materials in the aquifer matrix as a result of microbial activity and abiotic hydrolysis. Silica colloids are released during the diagenesis of amorphous silica. Similarly, radionuclide-bearing silica colloids are released from vitrified waste under simulated groundwater leaching conditions (11). Bacteria attached to aquifer solids may secrete various exocellular materials or release cell fragments to groundwater.

In addition, colloids can be released to groundwater if inorganic cementing agents that bind colloidal-sized materials to larger mineral grains dissolve or if stable aggregates are deflocculated. The reductive dissolution of iron oxide cements appears to be a mechanism by which colloids can be mobilized in natural waters or in contaminant plumes containing levels of DOC high enough to promote microbial activity and anoxic conditions. The dissolution of iron oxides in oxide-cemented sand under anoxic conditions liberates layer silicate clays previously bound to the aquifer matrix (7). Similarly, siliceous colloidal material is released into groundwater in a calcareous environment because infiltration of waters of different composition dissolve carbonate cements (12).

Attached subsurface bacteria may become unattached under high nutrient and carbon concentrations associated with contaminant plumes. Colloidal material also may be mobilized through disaggregation if the ionic strength of the groundwater is decreased or if the ion balance is shifted from one dominated by $\mathrm{Ca}^{2+}$ to one dominated by $\mathrm{Na}^{+}$. Permeability reductions in subsurface sediments and sandstones that accompany groundwater electrolyte changes have been ascribed to mobilization of colloids.

Colloids also can be moved to groundwater from the vadose or root zone (Figure 4). Humic substances can be flushed from upper, organic-rich soil horizons to the vadose and saturated zones during storms and major periods of infiltration such as snowmelt (13). Significant bacterial populations $\left(10^{4}-\right.$ $10^{7}$ microorganisms/g) have been 
found in groundwater zones (14), and their origin has, in part, been ascribed to migration from the upper soil zone.

Although humic substances and microbes can adsorb to mineral surfaces, their movement to a given depth apparently is facilitated by transport through preferential flow paths in porous media such as macropores and cracks associated with soil structure $(15,16)$. Layer silicate clays also can be mobilized from the soil zone by large storm events that lead to the infiltration of low ionic strength meteoric waters. The artificial recharge of groundwater by application of water to soils can lead to turbidity in groundwater and permeability reductions in soil, exacerbating the effects of mobilization of colloidalsized material (17).

\section{Stabilization and filtration}

The preceding discussion has shown how colloidal-sized material may be released from, transported to, or formed in groundwater. To be mobile over significant lateral distances and thus facilitate contaminant transport, suspended colloidal material must be stable (resisting aggregation with other like particles) and must not be susceptible to particle filtration in passing through porous media (Figure 3). Whether a particle will be stable, aggregated, filtered, or will settle in groundwater depends on a complex combination of density, size, the surface chemistry, the water chemistry, and the water flow rates. The complicated interdependency of these factors makes it difficult to predict particle behavior, based on current understanding and models; however, general concepts are well established for assessing these interactions qualitatively.

According to the theory of Derjaguin, Landau, Verwey, and Overbeek (the DLVO theory), the stability of a homogeneous colloidal suspension is determined by van der Waals attractive forces that promote aggregation and by electrostatic repulsive forces that drive particles apart. When electrostatic repulsions are dominant, the particles are electrostatically stabilized and remain in a dispersed state. Colloid stabilization therefore is influenced by particle mineralogy and surface chemistry, by other chemical factors controlling surface charge, and by the extent of the electrical double layer $(18,19)$. These chemical factors are summarized in Table 1 .

Particles are stabilized when their double layers are expanded (by decreasing electrolyte concentration and ionic strength) and when the net particle charge $\left(\sigma_{\mathrm{p}}\right)$ does not equal zero. The converse promotes coagulation. Counterion valence controls double-layer
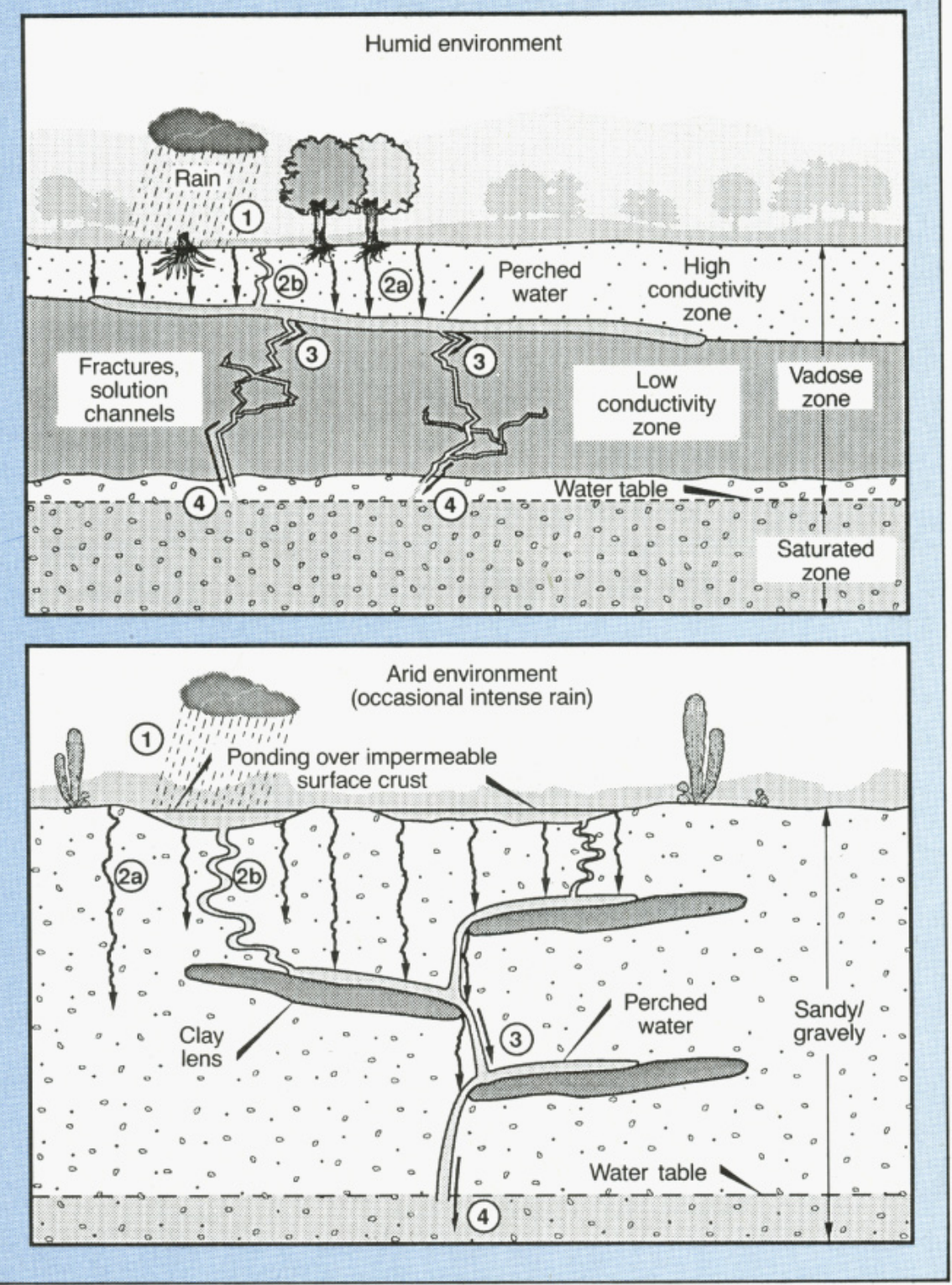

thickness, and divalent ions coagulate colloids at much lower aqueous concentrations than do monovalent ions (Schulze-Hardy rule).

Sorbable species (alkali earth cations, hydrolyzable metals such as $\mathrm{Fe}^{3+}$, and weak acid anions) and natural polyelectrolytes such as humic substances form surface complexes on colloidal material and influence net particle charge and stability. Strongly sorbing species may destabilize colloids at low concentrations and restabilize them at higher concentrations as their sorption induces charge reversal and an increase in $\sigma_{\mathrm{p}}$. Indeed, even under chemical conditions that should promote stability, coagulation of colloids in groundwater may occur if the surface charges on the suspended colloids are heterogeneous and permit interparticle electrostatic interactions. For example, the coagula- tion behavior of layer silicate clays is complicated because the edges and faces of the crystallites may carry opposite charge, giving rise to premature aggregation through edge-to-face association.

The destabilization of suspended colloids in groundwater as a result of factors such as increasing ionic strength or equivalent fraction of $\mathrm{Ca}^{2+}$ over $\mathrm{Na}^{+}$, or through strong ion adsorption, does not necessarily mean that they will be rendered immediately immobile. Coagulation kinetics are complex, and electrostatic interactions that occur during particle collisions are not well understood $(20)$. These interactions are a function of many variables, including particle concentration, particle size, and particle size distribution, all of which can influence the extent of particle-particle collisions in the ground- 
water. Moreover, destabilized colloids in groundwater still may be transported as aggregates if the aggregates are sufficiently small with respect to the pore diameters.

Even if hydrochemistry promotes their stability, suspended colloids can be mobile only if they are not filtered by porous media. Particle filtration in groundwater can occur by physical straining or by physical-chemical collection by attractive surfaces on the immobile matrix. Straining filtration is controlled by the pore dimensions and geometry relative to the colloid particle size. Straining filtration may be of secondary importance to physical-chemical collection for most groundwater colloids because their size is sufficiently small (typically $1 \mu \mathrm{m}$ or less) to permit them to move unimpeded through the large pore spaces of sandy aquifers (21). Straining filtration can be important for bacteria, which are often bigger than abiotic colloids (Figure 1).

Filtration by physical-chemical collection is controlled by electrostatic, chemical, or van der Waals forces. These phenomena are similar to those described for particle-particle interactions, except that the colloidal particles associate not with other particles but with the mineral or organic components of the immobile aquifer media. Collection of colloids is favored on surfaces of opposite charge. Negatively charged colloids are expected to be more mobile than positively charged ones because most groundwater matrices carry a net negative charge. Mobile groundwater colloids that have been observed to carry a negative charge include organic macromolecules, layer silicates, silicarich particles, bacteria, and iron oxides.

The adsorption of humic substances can impart a negative surface charge to colloids such as oxides, layer silicates, and calcium carbonate with positively charged surface sites, thereby increasing the stability and mobility of these particles. The adsorption of silica on iron and aluminum oxides may achieve a similar effect. Ryan (7) postulated that coatings of adsorbed humic. substances develop a negative charge on mobile layer silicate and iron oxide colloids in anoxic Atlantic coastal plain groundwaters. Nevertheless, colloidal material also may be collected by surfaces of like net charge because heterogeneous surface domains can exist with opposite charge where attractive forces exceed repulsive forces.

Stable colloids in groundwater can be mobile even under conditions that favor physical-chemical collection if particle surface collisions are minimized by slow interpore transport rates or if water movement occurs through preferen- tial flow paths with high relative velocity. Thus, Harvey et al. (22) found that larger microspheres were transported greater distances than were smaller ones in a permeable sand aquifer and suggested that the larger spheres experienced fewer diffusion-induced particle-surface collisions that could lead to attachment or collection (20). Microorganisms and organic macromolecules are transported through aquifers and intact soil cores more rapidly than chemical tracers are because their movement is limited to channels and to the secondary pore structure rather than extending through the intergranular pore space (22-24).

Theoretical considerations aside,

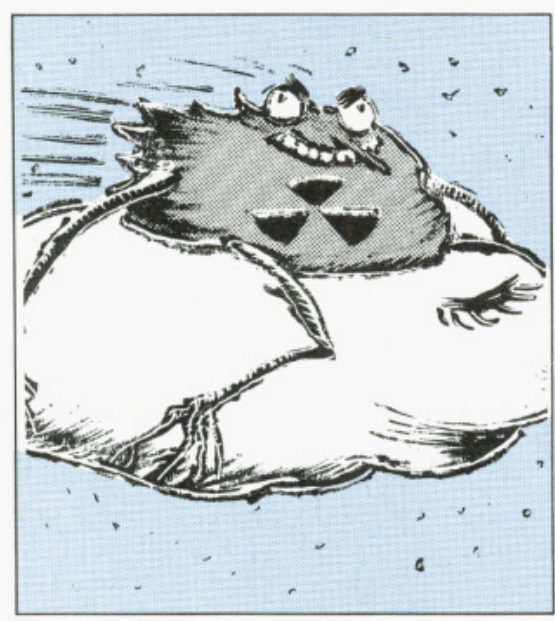

there is ample evidence that colloidalsized particles can move in aquifers. Bacteria have been reported to migrate up to $920 \mathrm{~m}$ and viruses up to $900 \mathrm{~m}$ (15). Asbestos fibers have been detected in an aquifer recharged from a reservoir containing high levels of fibers (25). Layer silicate clays mobilized from surface soils have been found to account for turbidity observed in wells several hundred meters distant from the recharge site (17). Humic substances can migrate rapidly in some aquifers. The migration of colloidalsized tannin and lignin (molecular weight $>2000$ daltons) from a waste pulp liquor migrated through a sand aquifer at the same rate as the groundwater flow (26). Rapid movement of both layer silicate clays and organic matter through the vadose zone also has been observed $(16,27)$.

\section{Colloids and contaminant transport}

If organic and inorganic colloids are present and mobile in groundwater, can they facilitate the transport of contaminants? Knowledge of the chemical mechanisms of contaminant-colloid interactions and our ability to predict the extent of the association vary widely depending on the nature of the contaminant and the colloid. Furthermore, much of the information is drawn from studies of colloidal material in surface waters; very few data are available for colloids isolated from groundwater.

Humic substances from surface water or soil bind hydrophobic organic contaminants, enhance the pollutant's apparent solubility in water, and reduce its apparent affinity for binding to sediment particles and to reverse-phase chromatographic columns and soil columns (28). Biopolymeric material arising from microbial cell lysis and fragmentation also sorb hydrophobic contaminants (29). The polyelectrolytic character of humic and fulvic acids enables them to associate with metal ions. Laboratory and field studies have demonstrated the significance of humics to the speciation of metals $(30)$ and radionuclides (31). Humic and fulvic acids from soil and sediment bind actinides strongly (32), and colloidal organic matter from lakes also binds radionuclides and inhibits their adsorption to sediments (31). Moreover, metals bind to functional groups on the cell surface of biological particles (33).

In other studies, inorganic particles identified as mobile colloids in groundwater have been shown to strongly adsorb contaminants. Layer silicate clays adsorb metallic and organic cations by ion exchange (34). Surfaces of iron, manganese, aluminum, and silicon oxide particles strongly adsorb certain metallic cations and organic and inorganic acid anions (35). Metals and organic acids may adsorb to the surface of calcium carbonate by complexation or exchange with structural ions (36). The humate coatings that mobilize layer silicate clays and oxide colloids alter their surface properties, making them more or less reactive with contaminant ions (37).

Contaminant binding to all of the substrates noted above is influenced to varying degrees by other solutes that may compete for common adsorption sites on the colloid surface. The importance of these colloids in facilitating contaminant transport in groundwater depends on the colloid surface area, the number of reactive sites per unit of surface, the preconditioning of surfaces by strongly bound cosorbates, and the strength of the contaminant-surface reaction. Unfortunately, few data of this type exist for groundwater colloids.

In some instances, the association of contaminants with colloidal material has been demonstrated in groundwater. Both transition element (manganese, cobalt) and lanthanide (cerium, europium) radionuclides have been associated with inorganic colloids in groundwater outside a nuclear detonation cavity at the Nevada Test Site (38). In groundwater several hundred meters downgradient from a uranium ore de- 
posit in Australia, uranium and daughter species such as thorium were found to be sorbed to iron- and silicon-rich colloidal particles between $0.018 \mu \mathrm{m}$ and $1 \mu \mathrm{m}$ in size (5).

Radioactive cobalt and uranium have been associated with high molecular weight organic material in groundwater near a disposal trench at the Oak Ridge National Laboratory (39). Likewise, radionuclides in groundwater of four contaminant plumes at the Chalk River Nuclear Laboratory in Canada were found to be associated with anionic organic ligands in the 500-10,000-dalton molecular weight range (40). A number of other studies have demonstrated that colloidal material isolated from groundwater is capable of sorbing organic and inorganic contaminants (41). Furthermore, insoluble metals and radionuclides may themselves form colloidalsized precipitates which may be mobile $(8,10)$.

\section{Developing a predictive capability}

Currently, scientific understanding is not adequate to identify, a priori, the groundwater zones in which colloids may exist and be important to contaminant migration. More observations are needed on suspended colloids in different groundwaters before the combined influence of groundwater chemistry, porous media lithology, and hydrology on colloid occurrence and behavior can be generalized to the predictive level. From what is understood, it appears that the colloid-mediated transport of contaminants may be important if

- contaminants associate strongly with particles (e.g., metals, radionuclides, and hydrophobic organic compounds);

- DOC levels are relatively high;

- aquifers are porous or fractured and flow rates are relatively high; or

- aqueous chemistry is dominated by sodium or undergoes natural or contaminant-associated alterations that would produce or mobilize colloids.

The effects of mobile colloids on contaminant migration cannot be predicted accurately with current models; several approaches, however, offer promise. Empirically, the colloid interaction can be factored into a distribution coefficient $\left(\mathrm{K}_{\mathrm{d}}\right)$ between the mobile and immobile phase, thus decreasing the retardation factor. This approach is appropriate for many hydrophobic contaminants that exhibit linear partitioning and the absence of competitive sorption with other like solutes. An advection-dispersion model has been developed that incorporates a mobile organic macromolecule and exhibits linear adsorption behavior for hydrophobic organic contaminants (24).

A constant $\mathrm{K}_{\mathrm{d}}$ approach, however, is not appropriate for most inorganic solutes because their sorption is nonlinear. Moreover, geochemical gradients in $\mathrm{pH}$, redox potential, and major ion composition (conditions favoring colloid mobilization) are likely to cause major changes in the $K_{d}$ between reactive solutes and both the aquifer matrix and the mobile colloids. More appropriately, colloidal material may be treated as a reactive component or ligand of the fluid phase. Mass action equations may be written between solutes (including contaminants and major ions) and colloids akin to those of aqueous and surface complexation (35), but this requires information on the concentration of colloid surface sites and equilibrium constants for surface complexes. These approaches are compatible with reaction-based surface complexation models (35) and geochemical transport codes (42). Other modeling approaches may be required if organic groundwater colloids, like humic substances, exhibit significant heterogeneities in surface properties and reactivity toward inorganic ions.

Calculations of colloid-facilitated transport are hampered by an inability to predict physicochemical dynamics of colloids in the groundwater zone. Surface complexation models and diffuse

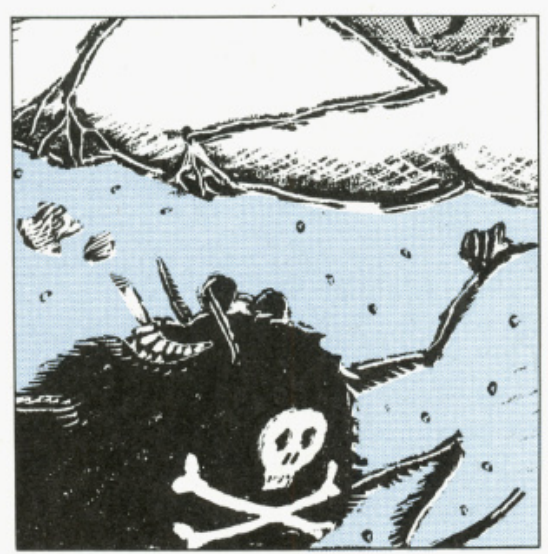

double layer models have been used to interpret coagulation phenomena of simple solute-solid combinations under static conditions. Although appropriate theory exists $(18,19)$, existing models do not predict coagulation under conditions relevant to groundwater. Calculations from filtration models deviate from observations when electrostatic effects predominate, especially when colloids and porous media have a like charge (20). Filtration models have not been applied to groundwaters in which the water flows slowly and horizontally rather than vertically. Clearly, the complexity of particle-particle and particle-media interactions is a significant challenge in developing a capability to predict the effect of mobile colloids on contaminant transport.
Even more daunting, however, are the difficulties in predicting preferential flow paths. These field-scale features are difficult to characterize and cannot be adequately simulated at a laboratory scale. Because of the size and surface charge that may promote filtration, colloid transport may be strongly influenced by preferential paths such as fractures, and these features need to be incorporated into models directly or stochastically.

\section{Applications to hazardous wastes}

The emphasis of this article has been on the potential role of colloids in enhancing the mobility of contaminants. The manipulation of colloid mobilization and deposition, however, could be a useful tool for the mitigation or remediation of waste sites. For example, if aquifer remediation is a goal, then removal of highly adsorbed contaminants from groundwater could be enhanced by the controlled mobilization, collection, and treatment of colloids from the affected groundwater zone. Colloid mobilization may affect aquifer permeability, however, and the benefits of contaminant solubilization versus pore clogging must be carefully assessed. In many cases, the removal of existing contaminants is not necessary or desirable. Effective waste management may require only that the migration of colloid-associated contaminants be contained within the boundaries of a controlled waste facility. It may be sufficient simply to limit the magnitude of this factor by treatments that promote deposition of colloids.

Therefore, an improved understanding of the mobilization and deposition of colloids in groundwater may be applied not only to solving problems of colloid-facilitated contaminant transport, but to developing strategies for the in situ isolation or remediation of hazardous wastes.

\section{Research needs}

The weakness of current predictive capabilities highlights the inadequacy of our understanding of mechanisms controlling the transport of highly retarded contaminants. Existing data suggest that mobile colloidal particles may be important mechanisms of contaminant transport through the vadose zone and within the saturated zone. However, this information is largely anecdotal and is inadequate either to evaluate the general significance of the phenomena or to develop a capability to include colloid-facilitated transport in computer models that predict contaminant migration in the subsurface. Future research must address a number of issues related to the occurrence and mobility of subsurface colloids and 
Key questions that require research (43)

Occurrence and properties of subsurface colloids

- Are colloids present in groundwater? If so, why, and how do we sample them without introducing artifacts?

- Can the presence of stable colloids be understood and predicted based on the mineralogy and hydrochemistry of specific subsurface environments?

- What is the composition, physicochemical nature, and abundance of colloidal particles in subsurface environments?

Mobility of subsurface colloids

- Do colloids move through aquifers?

- Can the chemical and hydrologic factors controlling the stabilization, transport, and deposition of colloidal particles be described and incorporated in predictive transport models?

Implications for contaminant transport

- Do mobile colloids sorb and transport contaminants?

- What is the capacity of groundwater colloids to bind contaminants?

- To what extent and how do chemical and radioactive wastes either precipitate as colloidal-sized particles or sorb to other colloidal material?

Implications for waste management

- Can an improved understanding of the biogeochemistry of subsurface colloids be applied to devise mitigation and remediation strategies based on manipulation of colloid mobilization or deposition?

their potential effect on the transport of contaminants (see box).

\section{Acknowledgments}

The authors are supported by the Subsurface Science Program of the Ecological Research Division, Office of Health and Environmental Research, U.S. Department of Energy, under contract DE-AC05840 R21400 with Martin Marietta Energy Systems, Inc., at Oak Ridge National Laboratory and under contract DE-AC0676RL0 1830 at Pacific Northwest Laboratory. Further information about the Subsurface Science Program can be obtained from Dr. F. J. Wobber, Office of Health and Environmental Research, ER75, U.S. Department of Energy, Washington, D.C. Publication No. 3069, Environmental Sciences Division, Oak Ridge National Laboratory.

\section{References}

(1) Nyhan, J. W. et al. J. Environ. Qual. $1985,14,501-09$.

(2) Nelson, D. M.; Orlandini, K. A. "Environmental Research Division Progress Report 1984-85," Anl-86-15; Argonne National Laboratory: Argonne, IL, 1986; sec. 3 , pp. 2,12 .

(3) Stumm, W. Environ. Sci. Technol. 1977, $11,1066-69$.

(4) Reynolds, M. D. M.S. Thesis; Massachusetts Institute of Technology: Cambridge, MA, 1985.

(5) Short, S. A.; Lowson, R. T.; Ellis, J. Geochim. Cosmochim. Acta 1988, 52, 2555-63.

(6) Backhus, D.; Gschwend, P. M.; Reynolds, M. D. EOS Trans. Am. Geophys. Union 1986, 67, 954.

(7) Ryan, J. N., Jr. M.S. Thesis; Massachusetts Institute of Technology: Cambridge, MA, May 1988.

(8) Gschwend, P. M.; Reynolds, M. D. J. Contam. Hydrol. 1987, 1, 309-27.

(9) Langmuir, D. Geol. Surv. Prof. Pap. U.S. 1969, 650-C, C224-C 235 .

(10) Ho, C. H.; Miller, N. H. J. Colloid Interface Sci. 1986, 113, 222-40.
(11) Avogadro, A. et al. In Environmental Migration of Long-Lived Radionuclides; International Atomic Energy Agency: Vienna, 1982; pp. 527-40.

(12) Gschwend, P. M.; Backhus, D.; MacFarlane, J. K. "Mobilization of Colloids in Groundwater Due to Infiltration of Water Near an Electric Generating Station,' Energy Laboratory Report MIT-EL 88004; Massachusetts Institute of Technology Energy Laboratory: Cambridge, MA, 1988

(13) Thurman, E. M. In Humic Substances in Soil, Sediment, and Water; Aiken, G. R.; McKnight, D. M.; Wershaw, R. L., Eds.; Wiley: New York, 1985; pp. 87104.

(14) Ghiorse, W. C.; Balkwill, D. L. Dev. Ind. Microbiol. 1984, 25, 213-24.

(15) Keswick, B. H.; Wang, D. S.; Gerba, C. P. Ground Water 1982, 20, 142-49.

(16) Jardine, P. M. et al. Soil Sci. Soc, J. 1989, 53, 317-23.

(17) Nightingale, H. I.; Bianchi, W. C. Ground Water 1977, 15, 146-52.

(18) Matijevic, E. J. Colloid Interface Sci. $1973,43,217-45$.

(19) Lyklema, J. In The Scientific Basis of Flocculation; Ives, K. J., Ed; Sijthoff and Noordhoff: Dordrecht, The Netherlands, 1978; pp. 3-36.

(20) O'Melia, C. R. In Aquatic Surface Chemistry: Chemical Processes at the Particle-Water Interface; Stumm, W., Ed.; Wiley: New York, 1987; pp. 385-401.

(21) McDowell-Boyer, L. M.; Hunt, J. R.; Sitar, N. Water Resour. Res. 1987, 22 , 1901-21.

(22) Harvey, R. W. et al. Environ. Sci. Technol. $1989,23,51-56$.

(23) Smith, M. S.; Thomas, G. W.; Ritonga, D. J. J. Environ. Qual. 1985, 14, 87-94.

(24) Enfield, C. G.; Bengtsson, G. Ground Water 1988, 26, 64-70.

(25) Hayward, S. B. J. Am. Water Works Assoc. $1984,76,66-73$.

(26) Robertson, W. D.; Barker, J. F.; LeBeau, Y. Ground Water 1984, 22, 191-97.

(27) Pilgrim, D. H.; Huff, D. D. Earth Surf. Processes Landforms 1983, 8, 451-65.

(28) Kile, D. E.; Chiou, C. T. In Aquatic Humic Substances: Influence on Fate and Treatment of Pollutants; Suffet, I. H.; MacCarthy, P., Eds.; Advances in Chemistry Series 219; American Chemical So- ciety: Washington, DC, 1989; pp. 131 58.

(29) Bell, J. B.; Terzos, M. Water Res. 1988, 22, 917-26.

(30) Perdue, E. M. In Aquatic Humic Sub stances: Influence on Fate and Treatment of Pollutants; Suffet, I. H.; MacCarthy, P., Eds.; Advances in Chemistry Series 219; American Chemical Society: Washington, DC, 1989; pp. 281-96.

(31) Nelson, D. M. et al. Environ. Sci. Technol. 1985, 19, 127-31.

(32) Nash, K. L.; Choppin, G. R. J. Inorg. Nucl. Chem. 1980, 42, 1045-50.

(33) Xue, H. B.; Stumm, W. Water Res. 1988, $22,917-26$

(34) Maes, A.; Gremero, A. In Geochemical Processes at Mineral Surfaces; Davis, J. A.; Hayes, K. F., Eds.; ACS Symposium Series 323; American Chemical Society: Washington, DC, 1986; pp. 25495.

(35) Sposito, G. The Surface Chemistry of Soils; Oxford University Press: New York, 1984

(36) Morse, J. W. Mar. Chem. 1984, 20, 91112.

(37) Dalang, F.; Buffle, J.; Haerdl, W. Environ. Sci. Technol. 1984, 18, 135-41.

(38) Buddemeier, R. W.; Hunt, J. R. Appl. Geochem. 1988, 3, 535-48.

(39) Means, J. L.; Crerar, D. A.; Duguid, J. O. Science 1978, 200, 1477-81

(40) Champ, D. R. et al. Water Pollut. Res. J. Can. 1984, 19, 35-54.

(41) Kim, J. I.; Buckau, G.; Zhuang, W. Proc. Symp. Mater. Sci. Res. 1987, 84, $747-56$.

(42) Cederburg, G. A.; Sheet, R. L.; Leckie, J. O. Water Resour. Res. 1985, 21, 10951104.

(43) McCarthy, J. F. "Role of Colloidal Particles in the Subsurface Transport of Contaminants: Five Year Subprogram Plan for the Department of Energy Subsurface Science Program"; U.S. Department of Energy: Washington, DC, 1989; DOE/ ER-0384.
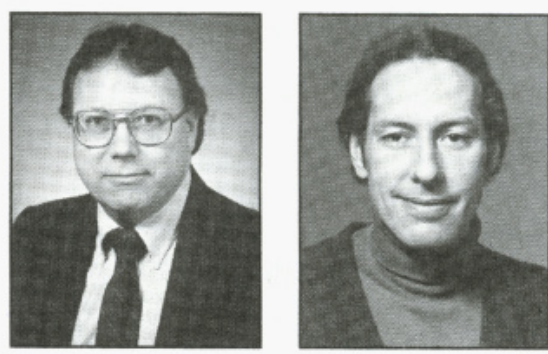

John F. McCarthy (l) is group leader for biological chemistry at the Environmental Sciences Division of Oak Ridge National Laboratory, which he joined in 1980 and where he has been directing a research project on colloid-facilitated transport for the Department of Energy since 1985. His research interests are in the fate and transport of contaminants and in the biological aspects of exposure to contaminants. McCarthy holds a B.S. from Fordham University and $a$ Ph.D. from the University of Rhode Island.

John M. Zachara $(r)$ is a technical group leader in the Geochemistry Section of Battelle's Pacific Northwest Laboratory, which he joined in 1979. His research interests include surface and colloid chemical reactions that control the migration of organic and inorganic contaminants in groundwaters and soils. Zachara obtained his B.S. at Bucknell University and his Ph.D. from Washington State University. 